\title{
Human Behavior in Organizations Related to Abraham Maslow's Hierarchy of Needs Theory
}

\author{
Altymurat $^{1}$, Mekaen Muhai ${ }^{1}$ Tituw Saparow ${ }^{1}$ \\ ${ }^{1}$ Faculty of Psychology, Turkmen State University (TSU), Turkmenistan
}

\begin{abstract}
The use of Abraham Maslow's hierarchy of needs principle in organisations is discussed in this essay. Physiological requirements, comfort needs, the desire to be loved and respected, and the need for self-esteem are also part of the hypothesis. This is what becomes a model on how to act in an organisation such that the organization's success improves in fulfilling the goal and purpose that has been set out to serve others. The company will function at its best when the requirements for confidentiality, convenience, and certainty are met, allowing the process of meeting user knowledge needs to operate smoothly. That almost all, regardless of their degree of need, desires peace, oversight, and consistent employment opportunities.
\end{abstract}

Keywords: Organization, Needs, Welfare

Received: March 10, 2021

Revised: April 23, 2021

Accepted: May 4, 2021

\section{Introduction}

Maslow broadened the definition of the homeostatic philosophy to include needs including comfort, affection, and self-respect that aren't usually associated with it. These deficiency needs, according to Maslow, are survival needs. Love and affection simply demonstrate that this need exists from birth, much like instinct.

At the most basic stage, there is a physiological need (need for oxygen, food, water, etc.) that is manifested by a lack (deficiency) of anything in the person's body. These requirements are often known as essential needs, and if they are not fulfilled in acute circumstances (such as hunger), the person in question can lose control over his own actions when all human capacities are mobilized and focused solely to meet his basic needs. In contrast, if these essential requirements are met to a large extent, a higher requirement, namely the need for a sense of protection, emerges (safety needs) (Ward \& Stewart, 2003; Standing, 1996).

The second form of need is for safety, security, protection, organization, order, predictability, and the absence of fear and anxiety, among other things. Humans establish rules, legislation, shares, systems, insurance, pensions, and other things to meet this need (Sinn, 2004; Hendrickson, 2003; Birchall, 2011). If these safety needs are not met over an extended period of time, or if so many of them are not met, a person's perspective on the environment will be influenced, and their actions may begin to be more pessimistic.

\section{The need to be loved and cherished}

Following the satisfaction of essential requirements and a sense of wellbeing, the need to be owned and cherished emerges (belongingness and love needs). All wishes to be in a warm and loving friendship, sometimes with strangers (Godbeer, 2009; Eagleton, 2011; Honig, 1987; McGinnis, 2003). He desires to be loved and to be loved. All wishes to be loyal mates and has to be a part of a community. All deserves to be a part of their own community, to have "roots" in society. Everyone wants to belong to a family, a village, a clan, or anything similar. Those who do not have a family will feel isolated, and others who do not attend school or jobs will 
feel that they are useless unemployed. The person's self-esteem would suffer as a result of this disorder.

\section{The Need for Self-Esteem}

If, on the other side, level three's requirements are mostly met, the desire for self-esteem will emerge (esteem needs). There are two types of self-esteem requirements. The first are the requirements for strength, mastery, maturity, self-assurance, and liberty. The second is the need for respect from others, as well as rank, fame, dominance, modesty, importance, and admiration from others. People who have their self-esteem needs met tend to be self-assured, independent of others, and still willing to grow in order to meet their highest desire, namely selfactualization (Lee, 2005; Locke, 2002; Ewen, 2013).

\section{Needs for Self-Actualization}

This need is made up of 17 meta needs that aren't grouped in any particular order, but rather complement one another. Apathy, boredom, despair, a lack of sense of humor, loneliness, selfishness, loss of taste, and other meta pathologies can result if the different meta needs are not fulfilled.

If it's reality, goodness, or elegance, the whole (unity), Uniqueness, Perfection, Need, Settlement, Justice, Order, Simplicity, Wealth (many combinations, many, no anything secret, all equally important), Effortless (relaxed, not tense), Playing (fun, leisure, humor), Selfsufficient

This theory was criticized during its progress. This is due to a leap in Maslow's highest needs pyramid, namely the desire to attain self-actualization. This need is distinct from the other four, which are both scientifically simple to comprehend. It's as if there's a missing connection between the fourth and fifth pyramids. It was as though a conceptual leap had been made. Furthermore, not all participants have the same desires; various people are motivated by different needs at the same moment, and frustration is a powerful motivator. This hypothesis isn't backed up by proof. Famines, musicians, and sometimes artists are not covered by this theory.

\section{Theoretical Consequences}

In relation to members' physiological needs, management must show sufficient appreciation, appropriate to purchase essential necessities of existence, and members must be provided with ample rest and food. Managers must provide members with assured job protection, a clean and sanitary work climate, and retirement insurance in order for them to feel financially protected. Managers must promote cooperation and plan group events in order to meet social needs. Managers must encourage and reward participants who meet and surpass their goals when it comes to the need for self-esteem. Managers may promote representatives to a higher rank than they previously had. Managers should have positions that challenge workers in order to best utilize their talents and imagination, which is related to the desire for self-actualization. Furthermore, chances for advancement must be given to them in order for them to advance in their professions.

Managers must then determine the participants' degree of needs, which can then be utilized as a source of inspiration. Everything motivation, according to Abraham Maslow, is a response to an individual's understanding of the five fundamental types of needs. According to Maslow, there are five types of fundamental needs that everybody has at any point in their lives. It's a complex holistic integration or mixture of hypotheses, according to Maslow's Hierarchy of Needs theory. Maslow's philosophy is named after the functional traditions of James and 
Dewey, which he mixed with concepts of Wertheimer, Goldstein, and Gestalt psychology, as well as the dynamism of Freud, Fromm, Horney, Reich, Jung, and Adler.

\section{Implementation of Maslow's Theory}

A leader must consider the idea of inspiration as a whole in order to construct a motivating work atmosphere in an organisation. The inspiration philosophy of Maslow and Clelland will assist a leader in determining the best method for inspiring subordinates. Since various levels of encouragement have an effect on different individual objectives, it may obstruct the achievement of the organization's common goals. The presence of Maslow and Clelland's philosophy of motivation in an operational sense may be a scientific guideline in creating human resource motivation in organisations. In a corporate sense, motivation encourages current human resources to perform at their best; this is critical since the organisation is a nonprofit knowledge service organization that places a premium on high customer satisfaction. As a result, developing inspiration in this way necessitates a theoretical paradigm that covers all individual needs.

The company will function at its best when the requirements for confidentiality, convenience, and certainty are met, allowing the process of meeting user knowledge needs to operate smoothly. That almost all, regardless of their degree of need, desires peace, oversight, and consistent employment opportunities.

It is a proud accomplishment to gain esteem for any human being. Many people put in years of effort only to receive one reward to show the audience that they are capable. Many people have quit their jobs or work without incentive because they do not get attention or compensation from their bosses while they are participants. The incentive element must be a cornerstone in the development of job motivation such that corporate objectives can be achieved collaboratively from the top down.

The awarding agency would assist the recipient organization in being more profitable. This is in line with Mikander's (2010) assertion that organization awards have a significant impact on participant results. Members that enhance their results can see an improvement in their jobs. The more the team develops and the organization's goals will be met, the more employees with job accomplishments there are.

Material and non-material awards are also possible. Material awards which provide sufficient usable position allowances, operating vehicle equipment, and special intensive support from the government and the parent agency where the company is located. Scholarships for research assignments, participation in seminars and courses to develop the competence of corporate resources are examples of non-material rewards. It may also take the form of offering resources for organisations to attain milestones and ranks that fulfill the criteria for promotion to institutional echelon IV, III, and II levels in the organizational sector, in addition to nonmonetary awards. Giving prizes has the effect of making the company work more to justify its survival by achieving proud accomplishments.

Providing organisations with a free room to communicate their potential may be one way to inspire them to work while still reducing relational stress. Members will think broadly in this situation and will not want to be constrained by rigid laws. Members choose jobs that enable them to demonstrate their talents and provide them with a range of tasks, freedom, and input on the outcomes of their work. Jobs with little challenges will easily confuse them; jobs with so many challenges, on the other hand, can contribute to boredom and disappointment. Members would feel more satisfied if their working environments are moderately challenging. 
As corporate organizations are willing to provide a room for freedom, that can make the process of self-actualization simpler for the organisation. Self-actualization is a mechanism in which an organisation is aided in developing its career as an intelligence agent, scientist, or competent instructor, capable of providing a variety of constructive input to the organization in the form of a positive representation of the organization to society. Direct organizational participation in the phase of cultivating group reading engagement may be an example of organizational self-actualization. Via the establishment of a reading garden that is maintained by the association as a whole, including all aspects of culture, community, and supporters.

The actualization phase that takes place inside the association will lead to attempts to establish cross-professional and science affiliations. In this situation, affiliation is a way to improve corporate consolidation in terms of both interpersonal partnerships and organizational objectives. The establishment of a partnership that has the potential to influence the development of more room for organizational movement. Since prospective organisations may need partnerships with other knowledge sources in order to disseminate information and overcome their limitations. The need for authority is part of the organization's attempt to persuade people to achieve personal interests that are also aligned with the organization's objectives. The need to gain authority, to be dominant, and to dominate other people is the source of power.

Individuals with high needs like being responsible, fail to control others, thrive in competitive and status-oriented environments, and are more concerned with authority and dominance over others than with successful results. The strength that can be attained will be legitimized by the accomplishments that have already been created. Even if the culture of the company is very competitive, as an organization holds a leading role, another organization can offer assistance. Abraham Maslow's ideas provide us with a detailed roadmap to exploring the desires that inspire people to be more precise in the workplace. The hierarchy of needs philosophy stresses the physical satisfaction of specific human needs.

\section{Implementation of Abraham Maslow's Hierarchy of Needs Theory on Improving Organizational Performance}

Within the structure of the corporate hierarchy, external refers to the outer environment in a vertical or horizontal manner. In contrast, the philosophy of needs, which looks at people more from the perspective of their ability to actualize themselves through the quest for high accomplishment, the force that is often connected, and the affiliation that is the glue in the corporate chain, reveals the burying of personal fulfillment to travel dynamically and fiercely compete. Maslow's thought is quite systematic towards disentangling individual desires in theory. The presence of thinking is well suited to explaining Maslow's ideas in terms of external needs that humans in general need. Both of these ideas address the structure of corporate growth from the outside, with a focus on putting more faith in internal human resources. Finally, since the organisation will continue to be colored by the complexities that shape modern organisations, it will grow and innovate dynamically.

\section{Conclusion}

The actualization phase that takes place inside the association will lead to attempts to establish cross-professional and science affiliations. In this situation, affiliation is a way to improve corporate consolidation in terms of both interpersonal partnerships and organizational objectives. The establishment of a partnership that has the potential to influence the development of more room for organizational movement. Since prospective organisations may need partnerships with other knowledge sources in order to disseminate information and overcome their limitations. As corporate organizations are willing to provide a room for 
freedom, that can make the process of self-actualization simpler for the organisation. Selfactualization is a mechanism in which an organisation is aided in developing its career as an intelligence agent, scientist, or competent instructor, capable of providing a variety of constructive input to the organization in the form of a positive representation of the organization to society.

\section{References}

Birchall, J. (2011). People-centred businesses. In People-Centred Businesses (pp. 1-19). Palgrave Macmillan, London.

Eagleton, T. (2011). Trouble with strangers: A study of ethics. John Wiley \& Sons.

Ewen, R. B. (2013). Personality: A topical approach: Theories, research, major controversies, and emerging findings. Psychology Press.

Godbeer, R. (2009). The overflowing of friendship: love between men and the creation of the American republic. JHU Press.

Hendrickson, A. R. (2003). Human resource information systems: Backbone technology of contemporary human resources. Journal of Labor Research, 24(3), 381-394.

Honig, L. (1987). No Friends, All Strangers. The Agni Review, (24/25), 15-30.

Lee, Y. A. (2005). Older persons' successful aging: Relationships among proximity of clothing to self, age identity, and self-actualization. Michigan State University.

Locke, K. J. (2002). Self-transcendence in relation to self-actualization and the effect on motivation in the church. The Southern Baptist Theological Seminary.

McGinnis, A. L. (2003). The friendship factor: how to get closer to the people you care for. Augsburg Books.

Sinn, H. W. (2004). The pay-as-you-go pension system as fertility insurance and an enforcement device. Journal of Public Economics, 88(7-8), 1335-1357.

Standing, G. (1996). Social protection in Central and Eastern Europe: a tale of slipping anchors and torn safety nets. Welfare states in transition: National adaptations in global economies, 225-255.

Ward, T., \& Stewart, C. (2003). Criminogenic needs and human needs: A theoretical model. Psychology, Crime \& Law, 9(2), 125-143. 